\title{
Paediatric virology and human papillomaviruses: An update
}

\author{
IOANNIS N. MAMMAS ${ }^{1}$, TINA DALIANIS ${ }^{2}$, SOTIROS G. DOUKAS ${ }^{3}$, \\ APOSTOLOS ZARAVINOS $^{4}$, VASSILIS ACHTSIDIS ${ }^{5}$, PRAKASH THIAGARAJAN ${ }^{6}$, \\ MARIA THEODORIDOU ${ }^{7}$ and DEMETRIOS A. SPANDIDOS ${ }^{1}$ \\ ${ }^{1}$ Department of Clinical Virology, School of Medicine, University of Crete, 71003 Heraklion, Greece; \\ ${ }^{2}$ Karolinska Institutet, Karolinska University Hospital, SE-117 77 Stockholm, Sweden; \\ ${ }^{3}$ Department of Surgery (Otolaryngology), Yale School of Medicine, New Haven, CT 06519, USA; \\ ${ }^{4}$ Department of Life Sciences, School of Sciences, European University Cyprus, 1516 Nicosia, Cyprus; \\ ${ }^{5}$ Department of Ophthalmology, Royal Cornwall Hospitals NHS Trust, TR1 3LQ Cornwall, UK; ${ }^{6}$ Neonatal Unit, \\ Division for Women and Children's Health, Noble's Hospital, IM4 4RJ Douglas, Isle of Man, British Isles; \\ ${ }^{7}$ First Department of Paediatrics, 'Aghia Sophia' Children's Hospital, \\ University of Athens School of Medicine, 11527 Athens, Greece
}

Received March 6, 2019; Accepted April 17, 2019

DOI: $10.3892 / \mathrm{etm} .2019 .7516$

\begin{abstract}
Almost 10 years ago, in October, 2008, the scientist who reported for the first time the association between human papillomaviruses (HPV) and cervical cancer, was awarded with the Nobel prize. In the years that followed, Professor Harald zur Hausen actively supported the value of the HPV vaccination in the prevention of different types of cancer and highlighted the necessity of its introduction in both girls and boys. However, to date, in the majority of countries, HPV vaccination among male adolescents has not been implemented into the national vaccination schemes, while in several countries, including Greece, the participation rate to HPV vaccination among female adolescents still remains low. Recent data indicate that catch-up HPV vaccination among young women has been extremely useful and has exhibited a significant effect in decreasing the prevalence of HPV. While the marketed current HPV vaccines prevent anogenital HPV infection, their impact on the natural history of oral HPV and their efficacy in preventing HPV-related head and neck carcinomas need to be further investigated. Juvenile onset recurrent respiratory papillomatosis, as well as HPV-associated conjunctival papillomas continue to be observed in childhood and their clinical management involves different therapeutic approaches with controversial outcomes. This review article provides an overview of recent views and advances on HPV infections
\end{abstract}

Correspondence to: Professor Demetrios A. Spandidos, Department of Clinical Virology, School of Medicine, University of Crete, 71003 Heraklion, Greece

E-mail: spandidos@spandidos.gr

Key words: Paediatric Virology, HPV, human papillomaviruses, vaccination, neonatal prematurity, respiratory papillomatosis, conjunctival papillomas and prevention in childhood that were presented at the "4th Workshop on Paediatric Virology' on Saturday September 22, 2018 in Athens, Greece.

\section{Contents}

1. Introduction

2. HPV prevalence following the initiation of HPV vaccination

3. Exploring effective interventions to increase HPV vaccination in adolescents

4. Infection with HPV and neonatal prematurity

5. Laryngeal HPV infection in neonates and children

6. Head and neck carcinomas as an additional HPV vaccination target

7. HPV and eye disorders in neonates and children.

\section{Introduction}

The '4th Workshop on Paediatric Virology' was held on September 22, 2018 in Athens, Greece in the context of the 23rd World Congress on Advances in Oncology and the 22nd International Symposium on Molecular Medicine. This was the 4th workshop that was organized by the Paediatric Virology Study Group (PVSG), with the aim to bring together virologists with paediatric health professionals and to encourage them to work together as an international network to promote paediatric health towards viral infectious diseases (1-3). The educational programme of the workshop delivered a wealth of new material from different sections of viral infections occurring in infancy and childhood. It was co-chaired by Professor Tina Dalianis, Professor of Tumour Virology at Karolinska Intitutet (Stockholm, Sweden), Professor Maria Theodoridou, Emerita Professor of Paediatrics at the 'Aghia Sophia' Children's Hospital in Athens, President of the National 
Immunisation Committee and former President of the Hellenic Paediatric Infectious Diseases Society (Greece), Dr Prakash Thiagarajan, Clinical Director and Consultant Neonatologist at Noble's Hospital on the Isle of Man (British Isles) and Dr Ioannis N. Mammas, Consultant Paediatrician on the island of Euboea (Greece) and Coordinator of the PVSG. The Workshop was enthusiastically supported by the Department of Clinical Virology of the University of Crete School of Medicine in Heraklion, Greece, the First Department of Paediatrics at the University of Athens School of Medicine in Athens, Greece and the PVSG.

The programme of this year's workshop consisted of two separate sessions. The first one was dedicated to the Spanish flu outbreak on the island of Skyros in 1918, which devastated one third of the island's population [Mammas et al (4)]. The second session examined human papillomaviruses (HPV) almost 12 years after the initiation of vaccination against HPV into clinical practice and its progressive implementation worldwide, mainly targeting young adolescent girls aged 10-14 years (5). In this review, we present an update on selected topics on HPV prevention and infections in childhood, as these were presented during the workshop (Table I).

\section{HPV prevalence following the initiation of HPV vaccina- tion}

In Sweden, in 2010, vaccination against HPV types 16 and 18 (any of the available vaccines) was subsidized and in 2012, a national school-based vaccination programme against HPV 16, 18,6 and 11 was launched for girls aged 10-12 years. In parallel a catch-up HPV vaccination programme was also initiated for young women up to the age of 26 years (6). To date, two studies had been performed at a youth clinic in Stockholm in order to examine base line cervical and oral prevalence of different HPV types in non-vaccinated and catch-up-vaccinated youth during the period 2008-2011 $(7,8)$. To later follow the effects of HPV catch-up vaccination, from 2013 three additional projects have been initiated, one among high school students and two from the same youth clinic as before (9-11). At the youth clinic from 2013-2015, 338 women of whom 71\% were catch-up-vaccinated against HPV donated cervical samples and 335 young women and 122 young men donated oral samples (11). Since 2017, a new collection of cervical samples is ongoing. A PCR bead-based multiplex assay was used to initially identify 24 and later $27 \mathrm{HPV}$ types and when possible, the data were compared to those obtained at the youth clinic in 2008-2011 (7-11).

Between 2013-2015, at the youth clinic, HPV16 cervical prevalence was significantly lower in women vaccinated against HPV compared to non-vaccinated women (5 and 18\% respectively, $\mathrm{P}=0.006$ ) (11). There was also a decrease in HPV16 prevalence among non-vaccinated women in the 2013-2015 year group compared to that in the 2008-2011 year group (18 and 34.7\%, $\mathrm{P}<0.0004)$. Similar trends were observed for HPV 18 and HPV 6. Oral HPV prevalence was lower in the 2013-2015 year group compared to that of the 2009-2011 year group (1.5 and $9.1 \%$ respectively, $\mathrm{P}=0.005$ ) and more similar to that $1.8 \%$ obtained among high school students $(8,11)$. Male urinary HPV prevalence has also been tested and was found to be low (6\%) and not efficient for use to follow changes in specific HPV types. Taken together, recent data indicate that catch-up HPV vaccination among young women has been extremely useful and has by itself gradually had a significant impact in decreasing HPV prevalence.

\section{Exploring effective interventions to increase HPV vac- cination in adolescents}

Although the coverage of HPV vaccination among adolescents has increased worldwide, it remains low compared to other recommended vaccines (12-14). To date, several multiple socio-demographic barriers to vaccination against HPV have been described (15-18). Insufficient knowledge about HPV infection and concerns about the safety of HPV vaccination have been proposed to be the most commonly reported barriers $(15,17,18)$. Concerns about the effectiveness of the vaccination, the low perceived risk of HPV infection and irregular preventive care have also been identified as potential barriers among parents. Financial issues have also been recently noted $(15,19)$. Before considering HPV vaccination, both parents and adolescents have often reported their need for more information of HPV infection and its prevention (20). They have consistently cited recommendations by their healthcare professionals as the most important factor in their decision-making, followed by the internet, school and mass media. In the healthcare setting, judgements by healthcare professionals as to whether to recommend the vaccine may restrict a young woman's access to the vaccine, irrespective of her own beliefs and preferences.

Effective intervention strategies to improve the uptake of vaccination against HPV should consider focusing on these socio-demographic barriers (12). Issues of trust require clear, accessible and sometimes culturally appropriate information about the HPV vaccination programme. School-based vaccination has also been proven to have yielded high HPV vaccination uptakes $(20,21)$. Financial issues may be overcome through universal healthcare systems offering the HPV vaccination free of charge. Further research is required in order to evaluate current policies and programmes, and to investigate novel strategies, which may be used to enhance acceptability and HPV vaccination uptake among adolescents.

\section{Infection with HPV and neonatal prematurity}

Preterm delivery is a major cause of neonatal morbidity and mortality. HPV infection is the most prevalent genital infection, particularly among young women of reproductive age, while in vitro and animal model experiments have provided compelling evidence of its harmful effects on pregnancy outcomes (22). The association between maternal HPV infection and neonatal prematurity was first evaluated almost 10 years ago (23-25). Since then, emerging evidence has suggested that some HPV types play an important role in the adverse outcomes of pregnancy contributing to infertility and increasing the risk of miscarriage (26). HPV infection has been proposed to be associated with both spontaneous preterm birth and the preterm rupture of membranes (26-28). It has also been demonstrated that abnormal cervical cancer screening in pregnancy may be associated with spontaneous preterm delivery and placental abnormalities $(29,30)$. However, other studies have failed to associate high-risk HPV infection or cervical intraepithelial neoplasia (CIN) with the 
Table I. The top key messages of the '4th Workshop on Paediatric Virology' on HPV infections and prevention in childhood.

HPV vaccination

HPV and neonatal prematurity

HPV-related JO-RRP

HPV-related conjunctival papilloma

HPV-related HNSCC as a vaccination target
Recent data indicate that catch-up HPV vaccination among young women in Sweden has been extremely useful and has by itself gradually exhibited an important effect in decreasing HPV prevalence.

Further research is required in evaluating current policies and programmes, and investigating novel strategies to enhance acceptability and HPV vaccination uptake among adolescents.

Comprehensive and high-quality evidence of such an effect of HPV on pregnancy outcomes may be an additional motivation for HPV vaccination; on the other hand, the absence of such an association could dispel anxiety and reassure HPV-infected pregnant women and clinicians.

Future prospective cohorts with larger samples sizes are required to ascertain the potential causality between maternal HPV infection and neonatal prematurity.

JO-RRP is a difficult and frustrating condition to treat; requiring multiple procedures to maintain airway and voice, and therefore a careful determination of the proper management method for each case is a fundamental step for the improvement of the quality of life in children suffering from JO-RRP. Carefully reviewing the existing data and assessing the advantages and disadvantages of each therapeutic approach, will help us develop an evidence-based therapeutic approach for the treatment of JO-RRP.

JO-RRP is related to vertical HPV transmission and in the following years, HPV vaccination is expected to have a significant contribution in the prevention of laryngeal papillomatosis in neonates and children.

A sessile limbal conjunctival papilloma must be observed or closely excised; if the lesion exhibits dysplastic or carcinomatous growth, then excisional biopsy with adjunctive cryotherapy is indicated.

While the marketed current HPV vaccines prevent anogenital HPV infection, their impact on the natural history of oral HPV, as well as their efficacy in preventing HPV-related HNSCC are at present unknown and warrant further investigation in the future.

HPV, human papilloma viruses; JO-RRP, juvenile onset recurrent respiratory papillomatosis; HNSCC, head and neck squamous cell carcinoma.

premature rupture of foetal membranes, placental abruption, cervical laceration and postpartum haemorrhage, infants with a low birth weight, amniotic fluid II-III degree, neonatal deformity and neonatal asphyxia between pregnant women with CIN and cervicitis (31-33), proposing that maternal HPV infection is not an independent risk factor for preterm birth.

A meta-analysis by Huang et al (34) indicated that both a positive HPV DNA status and an abnormal cervical cytology were associated with an increased risk of preterm births. In a recent meta-analysis by Xiong et al (35), despite that 8 out of 18 studies revealed no significant association between HPV infection and spontaneous abortions, subgroup analysis revealed that indiscriminate genotype HPV infection increased the ratio of spontaneous abortions. To date, in a recent New Zealand population-based retrospective study of 34,994 pregnancies by Lawton et al (36), preterm births were significantly lower for women who previously received the HPV vaccine, suggesting that HPV vaccination may be effective in reducing preterm births. In a cohort from Denmark (37), exposure to HPV vaccination during pregnancy was not associated with a significantly higher risk of adverse pregnancy outcomes than no such exposure. These unclear conclusions highlight the need for future prospective cohorts with larger samples sizes to ascertain the causality and pathophysiological studies and to explore the possible biological mechanisms involved. If this association is proven, HPV vaccination could be proposed to offer protection against preterm births. Comprehensive and high-quality evidence of such an effect of HPV on pregnancy outcomes may be an additional motivation for HPV vaccination (22). On the other hand, the absence of such an association could dispel anxiety and reassure HPV-infected pregnant women and clinicians.

\section{Laryngeal HPV infection in neonates and children}

HPV can cause skin warts, laryngeal papillomas, oral papillomas and anogenital warts in children (38-40). HPV-induced laryngeal papillomas in children are usually presented before the first year of life and most often demonstrate a recurrent course traditionally known as juvenile onset recurrent respiratory papillomatosis (JO-RRP) (41). The HPV types that are commonly identified in these lesions are 6 and 11 (41). The infection occurs probably via a vertical transmission of the virus, from 
an HPV-positive mother to her child (42). Laryngeal papillomas usually manifest with progressive hoarseness, stridor, or even severe airway obstruction, and the diagnosis is mainly made by visualization of the lesions during laryngoscopy that can be confirmed, if it is necessary, by biopsy. The prognosis is usually good with a low mortality rate. However, the clinical course is variable and often compromises a child's quality of life (41).

Different treatment approaches are usually employed with an aim of securing the airway patency and preserve the underlying laryngeal tissue. Surgical interventions, including microdebrider excision, laser ablation of the lesions, or a combination of both, are the classical approaches for JO-RRP (43). However, the recurrent course of the disease often requires multiple surgical excisions over a small period of time, increasing the frequency of complications, such as laryngeal sequelae. Other, less invasive approaches that have been suggested as effective, particularly as adjuvant therapies, include the following: Cidofovir (44), interferon (45) and indole-3-cardinol (46). However, the extensive side-effect profile of interferon limits its use. On the other hand, although the exact mechanisms of action of cidofovir are not yet well understood, it has been suggested to decrease the recurrence of papillomatosis when used in combination with other surgical interventions (44). However, the exact indications for the addition of cidofovir to the management plan have not yet been well established and possible risks and undesired effects should always be discussed with the patient and its legal guardians before a decision is made (43-45). A number of studies have also suggested the potential use of angiolytic lasers, cis-retinoic acid, bevacizumab (47), celecoxib (48) and even HPV vaccination (49), as potential therapeutic interventions (43). Studies have shown that when bevacizumab, a vascular endothelial growth factor A (VEGFA) inhibitor, is combined with invasive therapeutic interventions, a better control is provided $(43,47)$. Although celecoxib has been suggested to inhibit cyclooxygenase-2 (COX-2), which is often upregulated in papillomas, its effectiveness in reducing the growth or recurrence of papillomatosis remains unclear $(43,48)$. It has also been suggested that HPV vaccines, in addition to their significant contribution to the prevention of HPV-related diseases, including laryngeal papillomatosis, can also decrease the severity of recurrent laryngeal papillomatosis and can induce remission in some patients (49). In the following years, HPV vaccination is expected to have a significant contribution to the prevention of laryngeal papillomatosis in neonates and children.

\section{Head and neck carcinomas as an additional HPV vac- cination target}

HPV was only recently recognized as an emerging risk factor in the heterogenous tumour group of head and neck squamous cell carcinomas (HNSCC). HPV-positive tumours represent $5-35 \%$ of all HNSCC cases. Of these, $40-90 \%$ arise from the oropharynx, with rates that vary widely depending on factors such as the geographical area, the population in that area, the relative prevalence of environment-related squamous cell carcinomas (SCC) and detection assay. The incidence of HPV-positive oropharyngeal cancer, especially tonsillar and base of tongue cancer, mostly occurs in younger individuals aged between 40-55 years. Among the other extra-oropharyngeal subsites, HPV may also affect the supraglottic larynx (50), the marginal region of which is contiguous with the oropharynx, and it may account for the high-risk HPV infection rate which has been reported in laryngeal SCC $(51,52)$. The detection rates of HPV have recently been found to range between 13-91\% in oropharyngeal SCC (53). Among high-risk HPV types, HPV 16 is usually the most common, and this HPV type is found in almost $90 \%$ of the HPV-positive oropharyngeal cancers. At present, HPV 16 remains the only HPV type that is classified as cancer-causing in the head and neck; however, other high-risk HPV types have also been found in this region $(54,55)$.

Different carcinogenic mechanisms, including the HPV-encoded oncoproteins E6/E7, which interact with the host cell's p53 and pRb proteins, are most likely implicated in oropharyngeal carcinogenesis. Testing of the presence of high-risk HPV types in patients with HNSCC is increasingly becoming the standard of care. The molecular detection of HPV DNA is an optimal strategy with which to identify HPV using several assays with different sensitivity and specificity, including Southern transfer hybridization, dot blot hybridization, in situ hybridization (ISH), hybrid capture and more recently polymerase chain reaction (PCR) based technology (56). However, a combination of $\mathrm{p} 16^{\mathrm{INK} 4 \mathrm{~A}}$ expression and the molecular detection of HPV DNA yields sensitivity close to the gold standard methodology (detection of HPV E6 and E7 mRNA expression) to establish a diagnosis of HPV-related HNSCC (57). Differences in the biology of HPV-positive and HPV-negative oral squamous cell carcinoma may have implications for the management of patients.

Both in environmental-induced (smoking- and alcoholinduced) carcinogenesis and HPV oncogene-induced transformation, HNSCC is associated with a fundamental failure of immune surveillance, where tumour cells have escaped recognition/identification and lysis by the cytotoxic $\mathrm{T}$ lymphocytes (CTLs) of adaptive immunity. Activated CD8(+) CTLs are considered the critical effector cells of adaptive antitumor immunity. Activation of the naive, antigen-restricted CD8(+) CTLs first requires the binding of the $\mathrm{T}$ cell receptor (TCR) to its cognate tumour antigen (TA) in complex with human leukocyte antigen (HLA)I. Although the engagement between a tumour antigen and a TCR is required, this alone is not sufficient for the activation of CTLs and subsequent tumour cytolysis. The initial activation of CTLs is also dependent upon the balance between co-stimulatory and co-inhibitory signalling by dendritic cells and CD4(+) helper T cells, as well as on the 'freedom' from the suppression caused by CD4(+) regulatory T cells (Tregs) (57). HNSCC elicits T cell anergy in both peripheral and tumour-infiltrating lymphocytes (TILs). Functional defects in TILs include the low production and response to interleukin (IL)-2 (58) and vulnerability to spontaneous apoptosis, which is mediated through the Fas/Fas-ligand pathway (59); the low expression of CD3-f, OX40 and 4-1BB, co-stimulatory molecules required for signalling by the TCR $(58,59)$; and the high expression of co-inhibitory receptors, such as cytotoxic T-lymphocyte-associated antigen 4 (CTLA-4) and programmed-death-1 (PD-1) (57-61). The newly emerged anti-PD-1 immunotherapeutic drugs Nivolumab and Pembrolizumab, as well as the anti-CTLA-4 drugs Ipilimumab and Tremelimumab are all based on the release of these co-inhibitory receptors (57). 
The goal of therapeutic cancer vaccination is the inculcation of a persistent, tumour antigen-specific $\mathrm{T}$ cell response which kills tumour cells. To date, 5 promising vaccination strategies have entered clinical development in HPV-induced neoplasia, including two peptide vaccines, a detoxified E7 DNA vaccine, and two vector vaccines [pNGVL4a-CRT/E7 (Detox), TG4001 and Lm-LLO-E7] (62-65). In HPV-negative HNSCCs, overexpressed wild-type tumour-associated antigens (TAAs) such as p53, are potential vaccine targets. Despite treatment intensification for patients with HNSCC, including altered radiation fractionation and the addition of chemotherapy to radiation, physicians and patients still face the significant challenge of recurrent or secondary tumours arising within or in close proximity to previously irradiated tissues. The current management of HPV-induced HNSCCs recommends treatment de-escalation of HPV-induced HNSCCs, which can e.g., be achieved by reducing the total dose of radiotherapy in a concurrent chemoradiotherapeutic setting, by the use of radiotherapy and epidermal growth factor (EGFR) inhibitors instead of cis-platinum-based chemoradiotherapy or radiotherapy alone instead of chemoradiotherapy, and primary surgery $+/$ - de-intensified adjuvant treatment instead of up-front chemoradiotherapy (66-69). Nevertheless, the optimal treatment for patients with HPV-positive HNSCC remains uncertain. HPV-positive cancers appear to be more sensitive to chemoradiation, as the overall survival of patients with low-risk HPV-positive oropharyngeal cancers is almost double the overall survival of patients with high-risk HPV-negative cancers. This benefit in HPV-positive patients results from improved locoregional control rather than decreased distant metastasis. Since concurrent chemoradiation at least doubles the rate of acute and long term toxicities, less intense treatment regimens maximizing cure and decreasing toxicities are being investigated. In order to de-intensify the current standard of care, the reduction of the current radiation dose and/or the chemotherapeutic regimens would be needed.

While the marketed current HPV vaccines prevent anogenital HPV infection, their impact on the natural history of oral HPV, as well as their efficacy in preventing HPV-related HNSCC is less well studied (70). Future studies are expected to elucidate the potential role of HPV vaccination in the reduction of HNSCCs.

\section{HPV and eye disorders in neonates and children}

Conjunctival papillomas are benign epithelial tumours, which represent $7-10 \%$ of all conjunctival tumours (71-73). The virus can be inoculated into the conjunctiva of the new-born child during vaginal birth, while in children and adults, the mechanism of infection is believed to be self-inoculation via ocular contact with contaminated hands $(72,73)$. Conjunctival papillomas may be pedunculated (squamous or exophytic) or sessile (strawberry-like) and are associated with low-risk HPV types 6 and 11, while in adults the high-risk HPV types 16, 18 and 33 are more common (74). PCR and DNA sequencing technique are reliable for the detection of the causative HPV type $(74,75)$. Differential diagnosis includes benign tumours of the surface epithelium (i.e., keratoacanthoma and actinic keratosis), malignant lesions of the surface epithelium, such as squamous cell carcinoma of the conjunctiva (SCCC), lymphomas, vascular tumours (i.e., lymphangioma and capillary haemangioma), non-pigmented conjunctival melanomas and secondary tumours.
In childhood, conjunctival papillomas tend to be larger and multicentric compared with those in adults, causing red eyes and chronic irritation. No-touch surgical excision and adjunctive double freeze-thaw cryotherapy are the preferred methods of treatment. Recurrence can be minimized by complete tumour excision, cryotherapy and adjunctive oral cimetidine and/or interferon alfa-2b. According to their oncogenic potential, HPV may cause other ocular manifestations later on in life, such as SCCC and recurrent pterygia $(75,76)$. The prevalence of HPV in ophthalmic pterygia and SCCC is 18 and 33\%, respectively (77). A multi-step pathogenetic process, with the participation of genetic inheritance, p53 mutation, UV radiation and importantly, oncogenic viral infection has been proposed for the pathogenesis and recurrence of conjunctival pterygium $(76,77)$. According to this 'two-hit' hypothesis, UV radiation predispose individuals to this benign neoplastic disease (first hit), while the second hit is an oncogenic event mediated by viral infection in susceptible or compromised cells.

Papillomas, if left untreated, may spread onto the cornea or eyelid fornix with several signs of dysplasia such as keratinization (leukoplakia), symblepharon formation, inflammation or inverted papilloma (77). A small pedunculated conjunctival papilloma, cosmetically acceptable, may be observed, as it could regress spontaneously. A sessile limbal papilloma must be observed or closely excised, if the lesion shows dysplastic or carcinomatous growth, then excisional biopsy with adjunctive cryotherapy is indicated.

\section{Acknowledgements}

The authors would like to thank Professor Harald zur Hausen for reviewing our manuscript. The authors would also like to thank all the participants, who attended the workshop and provided feedback so that further work on improving the programme can be achieved in the future.

\section{Funding}

No funding was received.

\section{Availability of data and materials}

Not applicable.

\section{Authors' contributions}

INM, TD, PT, MT and DAS conceived and designed this review article. INM, TD, SGD, AZ and VA researched the literature, performed critical analysis and review of the literature and drafted the manuscript. TD, PT, MT and DAS critically revised the article for important intellectual content. All authors have read and approved the final manuscript.

\section{Ethics approval and consent to participate}

Not applicable.

\section{Patient consent for publication}

Not applicable. 


\section{Competing interests}

DAS is the Editor-in-Chief for the journal, but had no personal involvement in the reviewing process, or any influence in terms of adjudicating on the final decision, for this article. The other authors declare that they have no competing interests.

\section{References}

1. Mammas IN, Greenough A, Theodoridou M, Kramvis A, Rusan M, Melidou A, Korovessi P, Papaioannou G, Papatheodoropoulou A, Koutsaftiki C, et al: Paediatric Virology and its interaction between basic science and clinical practice (Review). Int J Mol Med 41: 1165-1176, 2018.

2. Mammas IN, Theodoridou M, Kramvis A, Thiagarajan P, Gardner S, Papaioannou G, Melidou A, Koutsaki M, Kostagianni G, Achtsidis V, et al: Paediatric Virology: A rapidly increasing educational challenge. Exp Ther Med 13: 364-377, 2017.

3. Mammas IN, Greenough A, Theodoridou M, Kramvis A,Christaki I, Koutsaftiki C, Koutsaki M, Portaliou DM, Kostagianni G, Panagopoulou P, et al: Current views and advances on Paediatric Virology: An update for paediatric trainees. Exp Ther Med 11: 6-14, 2016.

4. Mammas IN, Theodoridou M, Thiagarajan P, Melidou A, Papaioannou G, Korovessi P, et al: A paediatric influenza update 100 years after the Skyros island Spanish flu outbreak. Exp Ther Med 17: 4327-4336, 2019.

5. zur Hausen H: Papillomaviruses and cancer: From basic studies to clinical application. Nat Rev Cancer 2: 342-350, 2002.

6. Grün N, Du J, Ährlund-Richter A, Mirzaie L, Ramqvist T and Dalianis T: Human papillomavirus (HPV) prevalence in youth at a youth clinic after the initiation of HPV-catch up vaccination in comparison to previously obtained HPV prevalence in the same clinic and to that in high school youth in Sweden. Int J Mol Med 42: S16, 2018.

7. Ramqvist T, Du J, Lundén M, Ahrlund-Richter S, Ferreira J, Marions L, Sparén P, Andersson S and Dalianis T: Pre-vaccination prevalence of human papillomavirus types in the genital tract of 15-23-year-old women attending a youth health clinic in Stockholm, Sweden. Scand J Infect Dis 43: 115-121, 2011.

8. Du J, Nordfors C, Ährlund-Richter A, Sobkowiak M, Romanitan M, Näsman A, Andersson S, Ramqvist T and Dalianis T: Prevalence of oral human papillomavirus infection among youth, Sweden. Emerg Infect Dis 18: 1468-1471, 2012.

9. Nordfors C, Grün N, Haeggblom L, Tertipis N, Sivars L, MatteboM, Larsson M, Häggström-Nordin E, Tydén T, Ramqvist T, et al: Oral human papillomavirus prevalence in high school students of one municipality in Sweden. Scand J Infect Dis 45: 878-881,2013.

10. Grün N, Ährlund-Richter A, Franzén J, Mirzaie L, Marions L, Ramqvist T and Dalianis T: Oral human papillomavirus (HPV) prevalence in youth and cervical HPV prevalence in women attending a youth clinic in Sweden, a follow up-study 2013-2014 after gradual introduction of public HPV vaccination. Infect Dis (Lond) 47: 57-61, 2015

11. Grün N, Ährlund-Richter A, Franzén J, Mirzaie L, MarionsL, Ramqvist $\mathrm{T}$ and Dalianis T: Follow-up on oral and cervical human papillomavirus prevalence 2013-2015 in youth at a youth clinic in Stockholm, Sweden. Infect Dis (Lond) 48: 169-170, 2016.

12. Mammas IN, Theodoridou M, Sourvinos G and Spandidos DA Exploring effective interventions to increase adolescents' vaccination against human papillomavirus (HPV). Int J Mol Med 42: S17, 2018

13. Mammas IN and Spandidos DA: Paediatric Virology as a new educational initiative: An interview with Nobelist Professo of Virology Harald zur Hausen. Exp Ther Med 14: 3329-3331, 2017.

14. Zur Hausen H, Mammas IN and Spandidos DA: HPV vaccination in boys: Determining the clinical relevance of this strategy. Exp Ther Med 14: 3327-3328, 2017

15. Mammas IN, Theodoridou M, Koutsaftiki C, Bertsias G, Sourvinos G and Spandidos DA: Vaccination against Human Papillomavirus in relation to Financial Crisis: The 'Evaluation and Education of Greek Female Adolescents on Human Papillomaviruses' Prevention Strategies' ELEFTHERIA Study. J Pediatr Adolesc Gynecol 29: 362-366, 2016.
16. Einstein MH, Schiller JT, Viscidi RP, Strickler HD, Coursaget $P$, Tan T, Halsey N and Jenkins D: Clinician's guide to human papillomavirus immunology: Knowns and unknowns. Lancet Infect Dis 9: 347-356, 2009.

17. Fisher H, Trotter CL, Audrey S, MacDonald-Wallis K and Hickman M: Inequalities in the uptake of human papillomavirus vaccination: A systematic review and meta-analysis. Int $\mathrm{J}$ Epidemiol 42: 896-908, 2013.

18. Kessels SJ, Marshall HS, Watson M, Braunack-Mayer AJ, Reuzel R and Tooher RL: Factors associated with HPV vaccine uptake in teenage girls: A systematic review. Vaccine 30: 3546-3556, 2012

19. Mammas IN and Theodoridou M: Financial crisis and childhood immunization: When parents disagree. Acta Paediatr 102: e145-e146, 2013.

20. Gottvall M, Stenhammar C and Grandahl M: Parents' views of including young boys in the Swedish national school-based HPV vaccination programme: A qualitative study. BMJ Open 7: e014255, 2017.

21. Batista Ferrer H, Trotter CL, Hickman M and Audrey S: Barriers and facilitators to uptake of the school-based HPV vaccination programme in an ethnically diverse group of young women. J Public Health (Oxf) 38: 569-577, 2016.

22. Niyibizi J, Zanré N, Mayrand MH and Trottier H: The association between adverse pregnancy outcomes and maternal human papillomavirus infection: A systematic review protocol. Syst Rev 6: 53, 2017.

23. Mammas IN, Sourvinos G and Spandidos DA: Maternal human papillomavirus (HPV) infection and its possible relationship with neonatal prematurity. Br J Biomed Sci 67: 222-224, 2010.

24. Mammas IN and Spandidos DA: Fighting against human papillomavirus: The 25-year old contribution of the University of Crete School of Medicine. J BUON 20: 17-21, 2015.

25. Mammas IN, Sourvinos G and Spandidos DA: HPV infection and neonatal prematurity. Int J Mol Med 42: S37, 2018.

26. Bonde U, Joergensen JS, Mogensen O and Lamont RF: The potential role of HPV vaccination in the prevention of infectious complications of pregnancy. Expert Rev Vaccines 13: 1307-1316, 2014

27. Ambühl LM, Baandrup U, Dybkær K, Blaakær J, Uldbjerg N and Sørensen S: Human papillomavirus infection as a possible cause of spontaneous abortion and spontaneous preterm delivery. Infect Dis Obstet Gynecol 2016: 3086036, 2016.

28. Mosbah A, Barakat R, Nabiel Y and Barakat G: High-risk and low-risk human papilloma virus in association to spontaneous preterm labor: A case-control study in a tertiary center, Egypt. J Matern Fetal Neonatal Med 31: 720-725, 2018.

29. Zuo Z, Goel S and Carter JE: Association of cervical cytology and HPV DNA status during pregnancy with placental abnormalities and preterm birth. Am J Clin Pathol 136: 260-265, 2011.

30. Hong JN, Berggren EK, Campbell SL, Smith JS and Rahangdale L: Abnormal cervical cancer screening in pregnancy and preterm delivery. Paediatr Perinat Epidemiol 28: 297-301, 2014.

31. Hagensee ME, Slavinsky J III, Gaffga CM, Suros J, Kissinger P and Martin DH: Seroprevalence of human papillomavirus type 16 in pregnant women. Obstet Gynecol 94: 653-658, 1999.

32. Cho G, Min KJ, Hong HR, Kim S, Hong JH, Lee JK, Oh MJ and Kim H: High-risk human papillomavirus infection is associated with premature rupture of membranes. BMC Pregnancy Childbirth 13: 173, 2013.

33. Subramaniam A, Lees BF, Becker DA, Tang Y, Khan MJ and Edwards RK: Evaluation of human papillomavirus as a risk factor for preterm birth or pregnancy-related hypertension. Obstet Gynecol 127: 233-240, 2016.

34. Huang QT, Zhong M, Gao YF, Huang LP, Huang Q, Wang W, Wang ZJ and Yu YH: Can HPV vaccine have other health benefits more than cancer prevention? A systematic review of association between cervical HPV infection and preterm birth. J Clin Virol 61: 321-328, 2014

35. Xiong YQ, Mo Y, Luo QM, Huo ST, He WQ and Chen Q: The risk of human papillomavirus infection for spontaneous abortion, spontaneous preterm birth, and pregnancy rate of assisted reproductive technologies: A systematic review and meta-analysis. Gynecol Obstet Invest 83: 417-427, 2018.

36. Lawton B, Howe AS, Turner N, Filoche S, Slatter T, Devenish C and Hung NA: Association of prior HPV vaccination with reduced preterm birth: A population based study. Vaccine 36: 134-140, 2018.

37. Scheller NM, Pasternak B, Mølgaard-Nielsen D, Svanström H and Hviid A: Quadrivalent HPV vaccination and the risk of adverse pregnancy outcomes. N Engl J Med 376: 1223-1233, 2017. 
38. Doukas SG: Laryngeal HPV infection in children: A review of management and treatment of Juvenile Onset Recurrent Respiratory Papillomatosis. Int J Mol Med 42: S17, 2018.

39. Mammas IN, Sourvinos G and Spandidos DA: Human papilloma virus (HPV) infection in children and adolescents. Eur $\mathrm{J}$ Pediatr 168: 267-273, 2009.

40. Sinal SH and Woods CR: Human papillomavirus infections of the genital and respiratory tracts in young children. Semin Pediatr Infect Dis 16: 306-316, 2005.

41. Donne AJ and Clarke R: Recurrent respiratory papillomatosis: An uncommon but potentially devastating effect of human papillomavirus in children. Int J STD AIDS 21: 381-385, 2010.

42. Silverberg MJ, Thorsen P, Lindeberg H, Grant LA and Shah KV: Condyloma in pregnancy is strongly predictive of juvenileonset recurrent respiratory papillomatosis. Obstet Gynecol 101: $645-652,2003$

43. Ivancic R, Iqbal H, deSilva B, Pan Q and Matrka L: Current and future management of recurrent respiratory papillomatosis. Laryngoscope Investig Otolaryngol 3: 22-34, 2018.

44. Derkay CS, Volsky PG, Rosen CA, Pransky SM, McMurray JS Chadha NK and Froehlich P: Current use of intralesional cidofovir for recurrent respiratory papillomatosis. Laryngoscope 123: 705-712, 2013

45. Gerein V, Rastorguev E, Gerein J, Jecker P and Pfister H: Use of interferon-alpha in recurrent respiratory papillomatosis: 20-year follow-up. Ann Otol Rhinol Laryngol 114: 463-471, 2005

46. Rosen CA and Bryson PC: Indole-3-carbinol for recurrent respiratory papillomatosis: Long-term results. J Voice 18: 248-253, 2004

47. Sidell DR, Nassar M, Cotton RT, Zeitels SM and de Alarcon A High-dose sublesional bevacizumab (avastin) for pediatric recurrent respiratory papillomatosis. Ann Otol Rhinol Laryngol 123: 214-221, 2014.

48. Limsukon A, Susanto I, Soo Hoo GW, Dubinett SM and Batra RK: Regression of recurrent respiratory papillomatosis with celecoxib and erlotinib combination therapy. Chest 136: 924-926, 2009

49. Young DL, Moore MM and Halstead LA: The use of the quadrivalent human papillomavirus vaccine (gardasil) as adjuvant therapy in the treatment of recurrent respiratory papilloma. J Voice 29: 223-229, 2015

50. Bussu F, Sali M, Gallus R, Vellone VG, Zannoni GF, Autorino R, Dinapoli N, Santangelo R, Martucci R, Graziani C, et al: HPV infection in squamous cell carcinomas arising from different mucosal sites of the head and neck region. Is p16 immunohistochemistry a reliable surrogate marker? Br J Cancer 108: 1157-1162, 2013.

51. Almadori G, Cadoni G, Cattani P, Posteraro P, Scarano E, Ottaviani F, Paludetti G and Maurizi M: Detection of human papillomavirus DNA in laryngeal squamous cell carcinoma by polymerase chain reaction. Eur J Cancer 32A: 783-788, 1996.

52. Almadori G, Galli J, Cadoni G, Bussu F and Maurizi M: Human papillomavirus infection and cyclin D1 gene amplification in laryngeal squamous cell carcinoma: Biologic function and clinical significance. Head Neck 24: 597-604, 2002.

53. Mammas IN, Sourvinos G, Zaravinos A and Spandidos DA: Vaccination against human papilloma virus (HPV): Epidemiological evidence of HPV in non-genital cancers. Pathol Oncol Res 17: 103-119, 2011

54. Bouvard V, Baan R, Straif K, Grosse Y, Secretan B, El Ghissassi F, Benbrahim-Tallaa L, Guha N, Freeman C, Galichet L, et al, WHO International Agency for Research on Cancer Monograph Working Group: A review of human carcinogens - Part B: Biological agents. Lancet Oncol 10: 321-322, 2009.

55. Stransky N, Egloff AM, Tward AD, Kostic AD, Cibulskis K, Sivachenko A, Kryukov GV, Lawrence MS, Sougnez C, McKenna A, et al: The mutational landscape of head and neck squamous cell carcinoma. Science 333: 1157-1160, 2011

56. Zaravinos A, Mammas IN, Sourvinos G and Spandidos DA Molecular detection methods of human papillomavirus (HPV). Int J Biol Markers 24: 215-222, 2009.

57. Zaravinos A: An updated overview of HPV-associated head and neck carcinomas. Oncotarget 5: 3956-3969, 2014.

58. Baruah P, Lee M, Odutoye T, Williamson P, Hyde N, Kaski JC and Dumitriu IE: Decreased levels of alternative co-stimulatory receptors OX40 and 4-1BB characterise T cells from head and neck cancer patients. Immunobiology 217: 669-675, 2012.

59. Hoffmann TK, Dworacki G, Tsukihiro T, Meidenbauer N, Gooding W, Johnson JT and Whiteside TL: Spontaneous apoptosis of circulating $\mathrm{T}$ lymphocytes in patients with head and neck cancer and its clinical importance. Clin Cancer Res 8 2553-2562, 2002.
60. Reichert TE, Scheuer C, Day R, Wagner W and Whiteside TL: The number of intratumoral dendritic cells and zeta-chain expression in $\mathrm{T}$ cells as prognostic and survival biomarkers in patients with oral carcinoma. Cancer 91: 2136-2147, 2001.

61. Badoual C, Hans S, Merillon N, Van Ryswick C, Ravel P, Benhamouda N, Levionnois E, Nizard M, Si-Mohamed A, Besnier N, et al: PD-1-expressing tumor-infiltrating T cells are a favorable prognostic biomarker in HPV-associated head and neck cancer. Cancer Res 73: 128-138, 2013.

62. Kenter GG, Welters MJ, Valentijn AR, Lowik MJ, Berends-van der Meer DM, Vloon AP, Essahsah F, Fathers LM, Offringa R, Drijfhout JW, et al: Vaccination against HPV-16 oncoproteins for vulvar intraepithelial neoplasia. N Engl J Med 361: 1838-1847, 2009.

63. Voskens CJ, Sewell D, Hertzano R, DeSanto J, Rollins S, Lee M, Taylor R, Wolf J, Suntharalingam M, Gastman B, et al: Induction of MAGE-A3 and HPV-16 immunity by Trojan vaccines in patients with head and neck carcinoma. Head Neck 34: 1734-1746, 2012.

64. Wallecha A, French C, Petit R, Singh R, Amin A and Rothman J: Lm-LLO-based immunotherapies and HPV-associated disease. J Oncol 2012: 542851, 2012.

65. Maciag PC, Radulovic S and Rothman J: The first clinical use of a live-attenuated Listeria monocytogenes vaccine: A Phase I safety study of Lm-LLO-E7 in patients with advanced carcinoma of the cervix. Vaccine 27: 3975-3983, 2009.

66. Forastiere AA: Chemotherapy in the treatment of locally advanced head and neck cancer. J Surg Oncol 97: 701-707, 2008.

67. Leclerc M, Maingon P, Hamoir M, Dalban C, Calais G, Nuyts S, Serre A and Grégoire V: A dose escalation study with intensity modulated radiation therapy (IMRT) in $\mathrm{T} 2 \mathrm{NO}$, T2N1, T3NO squamous cell carcinomas (SCC) of the oropharynx, larynx and hypopharynx using a simultaneous integrated boost (SIB) approach. Radiother Oncol 106: 333-340, 2013.

68. Fakhry C, Westra WH, Li S, Cmelak A, Ridge JA, Pinto H, Forastiere A and Gillison ML: Improved survival of patients with human papillomavirus-positive head and neck squamous cell carcinoma in a prospective clinical trial. J Natl Cancer Inst 100: 261-269, 2008.

69. Psyrri A, Licitra L, Lacombe D, Schuuring E, Budach W, Ozsahin M, Knecht R, Vermorken JB and Langendijk JA: Strategies to promote translational research within the European Organisation for Research and Treatment of Cancer (EORTC) Head and Neck Cancer Group: A report from the Translational Research Subcommittee. Ann Oncol 21: 1952-1960, 2010.

70. Zaravinos A: HPV as an emerging risk factor in head and neck carcinomas: An additional vaccination target? Int J Mol Med 42: S40, 2018.

71. Achtsidis V and Kozanidou E: The involvement of human papilloma virus (HPV) in eye's disorders in neonates and children: An update. Int J Mol Med 42: S17, 2018.

72. Kaliki S, Arepalli S, Shields CL, Klein K, Sun H, Hysenj E, Lally SE and Shields JA: Conjunctival papilloma: Features and outcomes based on age at initial examination. JAMA Ophthalmol 131: 585-593, 2013.

73. Sjö NC, von Buchwald C, Cassonnet P, Norrild B, Prause JU, Vinding $T$ and Heegaard $S$ : Human papillomavirus in normal conjunctival tissue and in conjunctival papilloma: Types and frequencies in a large series. Br J Ophthalmol 91: 1014-1015, 2007.

74. Minchiotti S, Masucci L, Serapiao Dos Santos M, Perrella E, Graffeo R, Lambiase A and Bonini S: Conjunctival papilloma and human papillomavirus: Identification of HPV types by PCR. Eur J Ophthalmol 16: 473-477, 2006.

75. D Kalogeropoulos $\mathrm{C}$ and $\mathrm{M}$ Moschos $\mathrm{M}$ : Advances in diagnosis and treatment of HPV ocular surface infections. Med Hypothesis Discov Innov Ophthalmol 4: 31-35, 2015.

76. Chalkia AK, Spandidos DA and Detorakis ET: Viral involvement in the pathogenesis and clinical features of ophthalmic pterygium (Review). Int J Mol Med 32: 539-543, 2013.

77. Di Girolamo N: Association of human papilloma virus with pterygia and ocular-surface squamous neoplasia. Eye (Lond) 26: 202-211, 2012.

This work is licensed under a Creative Commons Attribution-NonCommercial-NoDerivatives 4.0 International (CC BY-NC-ND 4.0) License. 